\title{
THE EFFECT OF D-TUBOCURARINE UPON THE STATIC ELASTIC RECOIL OF THE THORAX*
}

\author{
H. I. A. Nisbet, D. A. Pelton, J. E. S. Relton and H. Levison $\nmid$ \\ WITH THE TECHNICAL ASSISTANCE OF G. VolgyesI
}

IN CHILDREN, the compliance of the lung is related to height and vital capacity ${ }^{1,2,3}$ as is the total compliance of the thorax. ${ }^{4}$ If the volume history of the lung is standardized before measurement of compliance early in anaesthesia, there is evidence from adult subjects that values for static compliance differ little from those reported in normal conscious subjects. ${ }^{5}$

It has been shown that in normal anaesthetized children, the compliance of the total thorax, lung, and chest wall are related to height and predicted vital capacity and furthermore, that lung compliance measured early in anaesthesia has a value similar to that reported for conscious children. ${ }^{6,7}$

This relationship allows compliance to be compared under anaesthesia in normal children and young children with cardiorespiratory disease who are difficult to study in the conscious state.

The anaesthetic technique involves the use of halothane, which has no effect upon lung compliance ${ }^{8}$ and d-tubocurarine, which has on occasion caused broncho-constriction $^{9}$ which may be associated with a decrease in the lung compliance. ${ }^{10}$

In dogs, d-tubocurarine has been found both to reduce lung compliance and to decrease collateral ventilation. ${ }^{11}$ In man, although this relaxant does not produce significant changes in the compliance of the total thorax ${ }^{12,13}$ the effects on the lung have not been differentiated from those on the chest wall. An effect upon the lung could be opposed by the effect of muscle relaxation upon the chest wall and abdomen.

Since any effect of curare upon the elastic recoil of the lung must influence the results of comparative studies in young children, the static elastic recoil of the total thorax, lung, and chest wall was measured before and after the intravenous administration of this agent to 10 normal children.

\section{METHODS}

The subjects studied were 10 children aged 7-15 years, with no evidence of cardio-pulmonary disease, who were undergoing orthopaedic operations.

Anaesthesia was induced with thiopentone, $5 \mathrm{mg} / \mathrm{kg}$, with atropine, $0.02 \mathrm{mg} /$ kg. A cuffed endotracheal tube was passed under succinylcholine paralysis and an oesophageal balloon inserted to the lower oesophagus. When spontaneous

*Paper read at the Anaesthetic Division, American Academy of Pediatrics - Chicago, 1969. Supported by a grant (Grant \#MA 3700) from the Medical Research Council of Canada. $\uparrow$ From the Research Division of Anaesthesia, The Hospital For Sick Children, Toronto, Ontario, Canada, and the Department of Anaesthetics and Paediatrics, University of Toronto. 
ventilation returned, it was positioned at a point when the maximum pressure swing was recorded from a Statham pressure transducer attached to a two-channel Sanborn recording system.

The patient was then hyperventilated with oxygen and halothane (1-1.5 per cent) until apnoeic, whereupon the lungs were distended several times with a volume of gas sufficient to secure a tracheal pressure of $30 \mathrm{~cm} \mathrm{H}_{2} \mathrm{O}$, measured by means of a second Statham transducer connected to the airway.

The lungs were then inflated and deflated in a stepwise fashion with increments of air delivered from a calibrated syringe, and the changes in oesophageal and tracheal pressure recorded when the pressure tracing showed a constant value. This was repeated several times until reproducible results were obtained. D-tubocurarine, $0.5 \mathrm{mg} / \mathrm{kg}$, was then injected intravenously and the measurements were repeated at intervals of 1-minute and 3-5 minutes after the injection.

From these measurements, graphs of the pressure-volume changes during distension of the lungs were constructed, and from these graphs the tracheal, oesophageal and trans-pulmonary (tracheal minus oesophageal) pressures were measured at lung volumes corresponding to functional residual capacity (FRC) plus 10 per cent of predicted total lung capacity (TLC) and FRC plus 20 per cent TLC.

The pressures measured one minute before the injection of curare were considered to be the primary control value and were assigned the value of zero change (Figures 1 to 3 ). The difference between these values and those measured two minutes before the injection of curare indicate the degree of variation found between repeated measurements in the period of apnoea induced by hyperventilation with oxygen and halothane. After the injection of curare, the changes in pressure after one minute and 3-5 minutes are displayed.

\section{RESULTS}

In the 10 cases studied, the mean pressure attributable to elastic lung recoil (trans-pulmonary pressure) at a lung volume of FRC +10 per cent TLC measured two minutes before the injection of d-tubocurarine was higher than the primary control value, measured one minute before injection $\left(+0.20 \mathrm{~cm} \mathrm{H}_{2} \mathrm{O}\right.$, sD $0.32 \mathrm{~cm}$ $\mathrm{H}_{2} \mathrm{O}$ ). After the injection, the trans-pulmonary pressure at this volume fell, both at 1 minute $\left(-0.14 \mathrm{~cm} \mathrm{H}_{2} \mathrm{O}\right.$; sD $\left.0.32 \mathrm{~cm} \mathrm{H}_{2} \mathrm{O}\right)$ and at $3-5$ minutes $(-0.12 \mathrm{~cm}$ $\mathrm{H}_{2} \mathrm{O}$ ) (Figure 1).

The mean pressure attributable to the elastic recoil of the thoracic (oesophageal pressure) cage at a lung volume of FRC +10 per cent measured two minutes before the injection of curare was higher than the primary control value measured one minute before injection $\left(+0.16 \mathrm{~cm} \mathrm{H}_{2} \mathrm{O}\right.$; sD $\left.0.37 \mathrm{~cm} \mathrm{H}_{2} \mathrm{O}\right)$. At 3-5 minutes after the injection of curare the oesophageal pressure was still higher than the primary control $\left(+0.22 \mathrm{~cm} \mathrm{H}_{2} \mathrm{O}\right.$; sD $\left.0.45 \mathrm{~cm} \mathrm{H}_{2} \mathrm{O}\right)$. One minute after the injection of curare, a greater rise was measured in mean oesophageal pressure ( $+0.36 \mathrm{~cm} \mathrm{H}_{2} \mathrm{O}$; sD $0.11 \mathrm{~cm} \mathrm{H}_{2} \mathrm{O}$ ) (Figure 2).

The mean pressure attributable to the elastic recoil of the total thorax (tracheal pressure) 2 minutes before the injection of curare was higher than the 


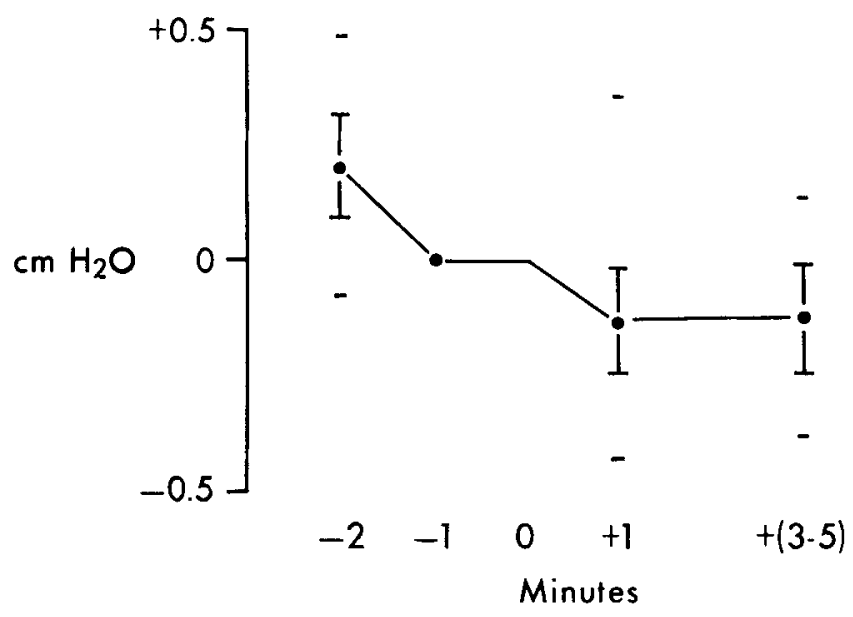

Figure 1. The change in pressure attributable to elastic lung recoil after curare was given at zero minutes. Measurements were made at a lung volume of FRC +10 per cent TLC. The means and one (bar) and two Standard Deviations are shown.

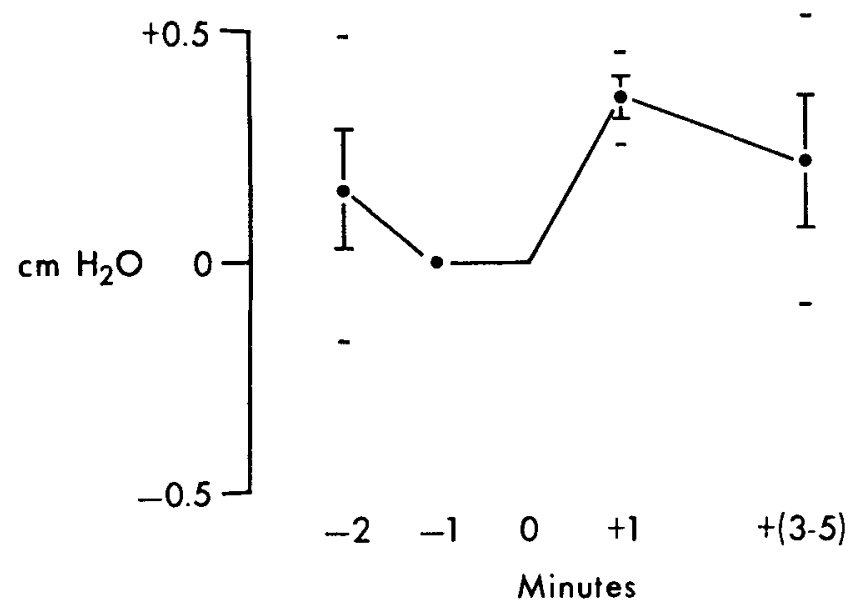

FIGURE 2. The change in pressure attributable to the elastic lung recoil of the thoracic wall after curare was given at zero minutes. Means and one (bar) and two Standard Deviations are shown. Measurements were made at lung volume of FRC +10 per cent TLC.

primary control value ( $+0.33 \mathrm{~cm} \mathrm{H}_{2} \mathrm{O}$; sD $0.43 \mathrm{~cm} \mathrm{H}_{2} \mathrm{O}$ ). After the injection the tracheal pressure remained higher than the control value both at 1 minute $\left(+0.22 \mathrm{~cm} \mathrm{H} \mathrm{H}_{2} \mathrm{O}\right.$; sD $0.34 \mathrm{~cm} \mathrm{H}_{2} \mathrm{O}$ ) and $3-5$ minutes ( $+0.10 \mathrm{~cm} \mathrm{H}_{2} \mathrm{O}$; sD $0.43 \mathrm{~cm}$ $\mathrm{H}_{2} \mathrm{O}$ ) (Figure 3).

Changes in these three pressures after the injection of curare were also investigated at lung volumes of FRC +20 per cent TLC. As with the measurements at the lower lung volume changes in the three pressures were very small and statistically insignificant both during the control period and after the injection of curare. 


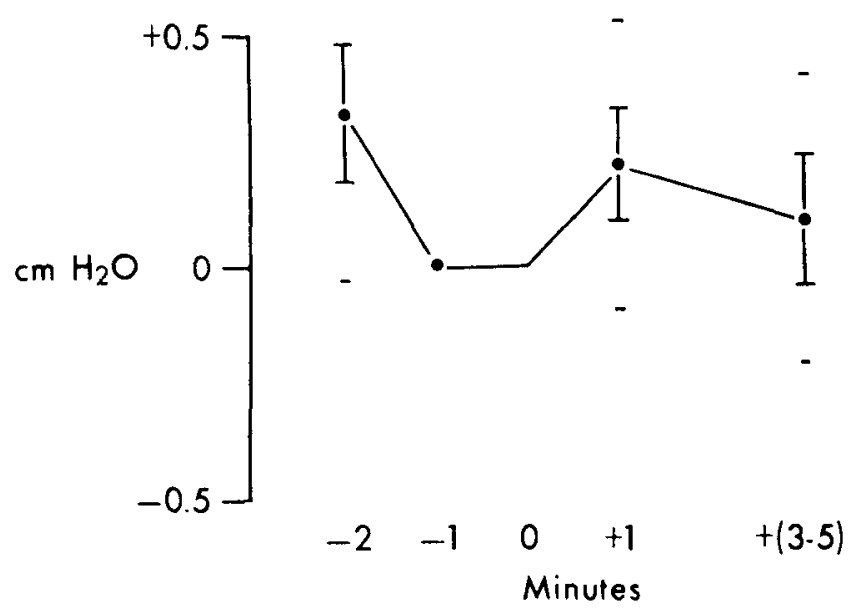

Figure 3. The change in pressure attributable to the elastic recoil of the total thorax after curare was given at zero minutes. Measurements were made at lung volumes of FRC +10 per cent rLc. The means and one (bar) and two Standard Deviations are shown.

\section{Discussion}

In animals Bernstein ${ }^{14}$ and Van de Woestijne and Trop ${ }^{15}$ showed that early in anaesthesia repeated inflation of the lungs allowed reproducible pressure volume measurements to be obtained. Clearly this is also true in children, since insignificant changes in the pressures distending the thorax were observed on repeated measurements at a given lung volume during the control period under halothane. Because the injection of curare was not followed by significant change from the pressures measured in the control period, it can be concluded that this agent did not alter the values for thoracic cage or lung compliance from those measured under halothane and oxygen.

In view of the small pressure change, it is possible only to note the tendency for the distensibility of the lungs to increase after the administration of curare. This, however, could well be due to the effect of further inflation of the lung, indicating a further small degree of adaptation. The tendency for thoracic wall distensibility to decrease (Figure 2) after curare is difficult to assess as it was only found at one minute after injection and not sustained in the measurement at 3-5 minutes. Werc it related to diaphragmatic paralysis and the effect of increased pressure from the intra-abdominal organs after curarisation, the rise in oesophageal pressure would have been expected to continue in the measurements between 3 and 5 minutes.

The results are in general agreement with the work of others who measured only the recoil of the total thorax after curare. Using somewhat different anaesthetic techniques and in different age groups, Nightingale and Richards ${ }^{\mathbf{1 3}}$ found no significant difference in total thoracic elastic recoil when measured in infants paralysed by succinylcholine or d-tubocurarine. Safar and Aguto-Escarraga ${ }^{12}$ 
found that the compliance of the total thorax did not increase after the acute administration of d-tubocurarine in adult patients under cyclopropane anaesthesia. Gerbershagen and Bergman ${ }^{16}$ measured total respiratory resistance and compliance in adult patients after the acute administration of curare in small and large doses. Their values for change in resistance during the first five minutes show much scatter, and values before and after curare were not significantly different. Static compliance was calculated by dividing the volume exhaled by the trans-thoracic pressure during a period of sustained thoracic inflation but the values were not reported nor are data concerning pressure and volume provided to permit evaluation of these results. It is not clear whether their method included repeated lung inflations before measurement in order to secure reproducible pressure volume measurements. Their results are, therefore, difficult to relate to the present report.

Since neither halothane ${ }^{8}$ nor d-tubocurarine have significant effects upon lung compliance during early anaesthesia, it is concluded that their use did not affect the values for lung compliance reported for children under general anaesthesia and myoneural block. ${ }^{6,7}$ Provided that similar studies show similar results in patients with scoliosis and cyanotic heart disease presently being investigated, it can be concluded that comparisons between these patients and the normal group will not be affected by the anaesthetic technique. The validity of this conclusion will need to be established in each group of patients studied.

\section{SUMMARY}

The use of the muscle relaxant $d$-tubocurarine has been associated with occasional reports of broncho-constriction and of low lung distensibility during anaesthesia. In order to determine whether the acute administration of this agent caused changes in lung and thoracic wall distensibility which were opposite in direction and therefore would not be reflected in a change in total thoracic distensibility, these values were measured before and after the injection of d-tubocurarine $(0.5 \mathrm{mg} / \mathrm{kg})$ during anaesthesia with halothane and oxygen.

The results showed that no significant changes from the control values occurred 3-5 minutes after the curare was given. It is therefore unlikely that curare, by causing broncho-constriction or interference with collateral ventilation, will invalidate studies of lung compliance during early anaesthesia in children.

\section{RÉSUMÉ}

Des rapports occasionnels ont fait état que le myorésolutif d-tubocurarine employé au cours de l'anesthésie pouvait être la cause d'une broncho-constriction et d'une faible distensibilité pulmonaire. Dans le but de dépister si l'administration soudaine de cet agent pouvait produire des changements sur la distensibilité du poumon et de la cage thoracique, lesquelles se font en direction opposée et, en conséquence, ne seraient pas décelables en présence d'un changement de la distensibilité thoracique totale, des évaluations ont été faites avant et après 
linjection de d-tubocurarine $(0.5 \mathrm{mg} / \mathrm{kg})$ au cours de l'anesthésie avec halothane et oxygène.

Les résultats ont démontré qu'il n'y avait pas de changements importants entre les données de contrôle et les données obtenues de 3-5 minutes après l'injection de curare. En conséquence, il semble invraisemblable que le curare, en causant une broncho-constriction ou un frein à la ventilation collatérale, puisse modifier les résultats des études de la compliance pulmonaire faites au début de l'anesthésie chez les enfants.

\section{REFERENCES}

1. Engstrom, I.; Karlberg, P.; \& Kraepelien, S. Respiratory Studies in Children: I. Lung Volumes in Healthy Children, 6-14 Years of Age. Acta. Paed. 46: 277 (1956).

2. Hellitesen, P. J.; Cook, C. D.; Friedlander, L.; \& Agathon, S. Studies of Respiratory Physiology in Children: 1. Mechanics of Respiration and Lung Volumes in 85 Normal Children 6 to 17 Years of Age. Pediatrics. 28: 80 (1958).

3. Kamel, M.; Weng, T.-R.; Featherby, E. A.; Jackman, W. S.; \& Levison, H. Relationship of Mechanics of Ventilation to Lung Volumes in Children and Young Adults. Scand. J. Resp. Dis. 50: 125 (1969).

4. Cherniac, R. M. \& Brown, E. A Simple Method of Measuring Total Respiratory Compliance: Normal Values for Males. J. Appl. Physiol. 20: 87-91 (1965).

5. Foster, C. A.; Heaf, P. J. D.; \& Semple, S. J. G. Compliance of the lung in Anaesthetised Paralysed Subjects. J. Appl. Physiol. 11: 383 (1957).

6. Niseet, H. I. A.; Pelton, D. A.; \& Levison, H. Pressure volume relationships of the thorax in normal children under general anaesthesia. Proc. Can. Soc. Clin. Investig. p. 56 (1969).

7. Nisbet, H. I. A.; Levison, H.; \& Pelton, D. A. Thoracic Wall Compliance in Children. Acta Anaes. Scand. Suppl. 37: 286 (1970).

8. Patterson, R. W.; Sullivan, S. F.; Malm, J. R.; Bowman, F. O.; \& Papper, E. M. The Effects of Halothane on Human Airway Mechanics. Anesthesiol. 29: 900 (1968).

9. Landmesser, C. M.; Converse, J. P.; \& HARMel, M. H. Quantitative evaluation of broncho-constrictor action of curare in anesthetised patient. Anesthesiol. 13: 275 (1952).

10. ANthonisen, N. R. Changes in compliance in rabbits subjected to acute bronchoconstriction. J. Appl. Physiol. 18: 539 (1963).

11. Call, E. P.; Lindskog, C. E.; \& Liebow, A. A. Some physiologic and pharmacologic aspects of collateral ventilation. J. Thor. and Cardio-vasc. Surg. 49: 1015 (1965).

12. Safar, P. \& Aguto-Escarraga, L. Compliance in apnoeic anesthetised adults. Anesthesiol. 20: 283 (1959).

13. Nightingale, D. A. \& Richards, C. C. Volume-pressure relations of the respiratory system of curarised infants. Anesthesiol. 26: 710 (1965).

14. Bernstern, L. The elastic pressure volume curves of the thorax of the living rabbit. J. Physiol. 138: 473 (1957).

15. VAN DE Woestrjne, K. P. \& Trop, D. Time dependence of the variations during forced inflations of the respiratory pressure volume curve in the dog. Arch. Int. Physiol. Biochem. 75: 416 (1967).

16. Gerbershagen, H. U. \& Bergman, N. A. Effect of d-tubocurarine on respiratory resistance in anaesthetised man. Anesthesiol, 28: 981 (1967). 